\title{
Promoting resilience and emotional wellbeing of transgender young people: research at the intersections of gender and sexuality
}

\begin{abstract}
Within lesbian, gay, bisexual and transgender (LGBT) research there is increasing healthrelated scholarship on trans lives, with a growing awareness of the impact of health inequalities on trans wellbeing. The aim of the paper is to provide greater understanding of transgender young people's views of what is needed to promote their emotional wellbeing and resilience by undertaking specific analysis of data collected as part of wider research with young people $(n=97)$. The study utilised participatory qualitative methods with a cross sectional design generating data via a focus group with trans youth $(n=5)$, followed by thematic analysis. Findings suggest that both individual and collective capacities or resources enable and sustain resilience and wellbeing for trans young people. The adversity trans youth face is present in school, the community and in healthcare, but they are able to find places where they feel safe and connected to others. Practitioners, teachers and school nurses are well positioned to facilitate structural change in alliance with trans youth to promote resilience. Research results were utilised to inform health improvement, commissioning and service delivery.
\end{abstract}

\section{Introduction}

In Western welfare systems heterosexual norms are embedded in the provision of health, education and social care (Rondahl 2011, Johnson and Browne 2012, Zeeman et al. 2014). Heterosexuality is based on the assumption that biological sex (male and female) aligns with gender identities assigned at birth, as heard in expressions such as 'it's a boy or it's a girl' (Butler 1999:151). However for some young people, their biological sex, assigned gender and gender expression do not naturally align. As a result, these young people fall outside the norm. The system that sustains the norm (heteronormativity), renders the lives of LGBT (lesbian, gay, bisexual, trans), queer and intersex people invisible (Butler 1993, Butler 1999).

Central to this system is the biomedical discourse that continues to shape healthcare structures and related practices to generate health and illness identities, and healthcare subjects (Fish 2008), with bodies that either matter, or do not matter (Butler 1993). With 
escalating costs in healthcare, most western healthcare systems have recently sought to increase people's abilities to promote their own health, wellbeing and self-care (PHE 2014). With growing recognition of the social determinants of health inequalities and the importance of interventions across the lifespan, but particularly in the early years, there has been mounting emphasis on health promotion activities for young people that take place in settings such as schools and local communities (Marmot 2010).

This paper presents a study aiming to understand how resilience and emotional wellbeing of trans young people manifested in school, health environments and community settings. The interaction of personal, interpersonal and structural factors that enable and sustain resilience were considered, but also the factors that restrict or curtail the resilience and emotional wellbeing of trans youth. This research engaged young people to inform health improvement, commissioning and service delivery (Sherriff et al. 2015).

\section{Background}

In a binary-gendered society, people are perceived as either male or female biologically, and as men or women in terms of gender. A further assumption is that this division into two genders is consistent with an opposite-sex orientation or a heterosexual identity (Nagoshi et al. 2012). This match between assigned gender at birth and our biological bodies has also come to be termed cisgender, and is used to describe people whose sex assigned at birth matches or is aligned with societal expectations of gendered norms related to gender identity and gender expression (Singh et al. 2015).

Queer and poststructural feminist theorists like Butler (1999, 2004), have attempted to deconstruct these concepts, in part for what they reveal more generally about the concept of gender, but especially for the forms of exclusion that follow gender variance (Nagoshi and Brzuzy 2010). Feminists have argued that the normative reproduction of gender supports and enables the regulation of sexuality (Hall et al. 2013). Therefore 'undoing gender' has meant making the lives of those seen as 'other' viable. These theories have sought to further challenge binary models of gender and to theorise gender as performative, fluid and evolving (Butler 2004, Namaste 2009).

Transgender lives are central to these theorisations, as the term transgender or trans refers to a separation between biological sex, gender identity and related roles. They are terms 
commonly used to describe people whose gender identity and/or gender expression do not conform to societal expectations for the sex they were assigned at birth. As a result some trans people identify with the opposite gender, or they might not be fixed on any one position, or they might be neither male or female and identify as queer or trans instead (Levitt and Ippolito 2014). Some transgender people are also transsexual, seeking sex-reassignment surgery and they can be at any stage of the process from pre-transition, transitioning to operative or post-operative (Nagoshi et al. 2012).

Therefore, trans reflects an evolving gendered identity and/or gender expression, with the understanding that for some young people in particular, their gender variation is not part of a life narrative of gender transitioning. However, for others being trans might include a desire to live as a member of the opposite sex, where gender identity and secondary sexual characteristics become aligned during surgery (Johnson and Browne 2012). Here being trans could signify a process of 'transitioning that has no end' (Salih and Butler 2011:348), where people constantly reinvent themselves. Consequently, trans lives often span a range of evolving gender expressions such as:

transsexual, transvestite, gender queer, female drag, male drag, cross-dressing and butch/femme practices (Hines 2010:598).

For the majority of people, gender identity paves the way for their sexuality to follow, in assumed heterosexuality, a process understood as heteronormativity. Queer scholarship combines with feminist theories to question heterosexual norms that assume sexuality follows on from gender. For trans people, the body (sex) is no longer fixed and can be changed. The secondary sexual characteristics of trans people can be altered (Butler 1993, Butler 1999). Therefore, any research with trans people has to consider the intersections of each individual's gendered identity and sexuality, and how they self-identify to inform their specific health needs. Transgender people's lives challenge the simplistic heteronormative divide and both complicate or trouble these assumptions (Dhaenens 2013). By queer theory destabilising the relationship between sex, gender and sexuality, it becomes apparent that the gender identification and sexuality of trans people is multifaceted and constantly evolving. While research with trans youth exists (Singh 2013, Singh et al. 2014), the emotional health and wellbeing of trans people is often poorly understood due to the complexities involved with fluid notions of their identity, and their sense of self, or subjectivity (Namaste 2009, Hines 2010). 


\section{Trans health needs}

Although trans lives have increasingly gained attention in the media, literature and research, trans health needs are sometimes subsumed by LGBT research, due to problematic assumptions that their needs are comparable (Johnson and Browne 2012). The review that follows initially explores LGBT health needs and is followed by specific trans related research. A meta-analysis by King et al. (2008) found significant health inequalities amongst LGBT people in relation to their experience of mental health problems, where a significantly higher risk of mental disorder, suicidal ideation, substance misuse and deliberate self-harm exists, compared to their heterosexual peers (King et al. 2008).

Recent research undertaken with more than 2000 LGBT participants in the UK, explored the risk and resilience factors that affect the health of LGBT people disproportionately (Nodin $e t$ al. 2015). The study found that LGBT young people under the age of 26 are more likely to attempt suicide and to self-harm than their heterosexual peers. The incidence of suicide attempts were much higher amongst LGBT young people, where 34\% made at least one suicide attempt during their lives compared to $18 \%$ of heterosexual young people. Amongst trans young people, $48 \%$ had made at least one suicide attempt (Nodin et al. 2015). This research is supported by other studies (Bauer et al. 2014, Bauer et al. 2015) that found significantly increased levels of suicidal ideation amongst trans people in Canada. Rates indicate $35 \%$ of trans people had considered suicide and $11 \%$ attempted suicide in the past year. These figures are consisted with research in Europe and the USA, where 22-43\% of trans people reported a history of suicide attempts (Bauer et al. 2015).

According to Whigmore et al. (2009), a number of factors contribute to suicide attempts of young people including negative experiences of coming out, homophobic and transphobic bullying, and struggles about being LGBT within the family, at school or in peer groups. There was a lack of awareness and training amongst teachers and health practitioners that made responses to the distress of trans youth insufficient (Whigmore et al. 2009). Resources that are inclusive and take account of the lives and challenges faced by LGBT young people are particularly limited outside of LGBT specialist service provision. Importantly, constructive interventions by health practitioners are known to be essential to help young people recover more quickly from mental health problems (Reczek and Umberson 2012, Nodin et al. 2015). 
Therefore, whilst research with LGBT people has uncovered joint concerns over experiences of marginalisation, exclusion and stigmatisation (Johnson and Browne 2012), a number of studies indicate that trans people experience significantly higher rates of bullying and marginalisation, they feel socially isolated more often, or have a decreased sense of connectedness to their communities (Browne and Lim 2008a, Bauer et al. 2014, Bauer et al. 2015, Nodin et al. 2015, Scheim and Bauer 2015). Trans young people may have difficulty finding trans peers, or information about trans related issues (Hackimer and Proctor 2015).

While trans people are known to have considerably higher risks of stress arising from both overt and covert discrimination and prejudice in health care, trans people may additionally experience transphobia as internalised feelings of shame and blame, leading to anticipation of stigma, which in turn, ends in higher rates of self-harm and suicide (McDermott 2014, Fish and Karban 2015). Consensus amongst researchers suggests social stigma, prejudice and discrimination experienced at both an individual and institutional level is associated with the non-normative gender expressions of trans people, and is in part responsible for health inequalities and negative health outcomes (Haas et al. 2011, Bauer et al. 2015, Nodin et al. 2015).

However, trans health research commonly focuses on psychopathology as most studies are undertaken in medical environments such as gender clinics or sexual health centres (Pitts et al. 2009). Frequently research over-estimates levels of psychopathology such as anxiety or depression in trans people compared to the general population, or research medicalises trans people's lives and their physical, emotional and mental health (Pitts et al. 2009). While homosexuality has been removed from the DSM V (Diagnostic and Statistical Manual of Mental Disorders) (APA 2013), and ICD-10 (International Statistical Classification of Diseases and Related Health Problems) as a sexual disorder, the medicalisation of sexuality persists by retaining gender dysphoria as diagnosis. Here, trans young people are located in consultation rooms, clinics and hospitals where health practitioners govern access to specialist services and the interventions required to alter their bodies (Johnson and Browne 2012).

In New Zealand and Australia, a survey of trans people's health and wellbeing revealed a complex picture with major mental health issues such as depression and stigma, some of which emanates from healthcare professionals (Pitts et al. 2009). Trans young people are at risk of marginalisation when they access health services due to a lack of understanding by 
those whom they encounter. This highlights the need to develop health services that are trans friendly and inclusive (Browne and Lim 2008a). Recognition of the complexity of gender identity, as well as knowledge of trans health needs remains low amongst education and health care providers (Sherriff et al. 2011, Singh et al. 2011). Research has identified a need for specialist training of teachers, school nurses and other health practitioners to address the needs of trans youth (Whigmore et al. 2009, Sherriff et al. 2011). While there is increasing scholarship on trans lives, there remains much scope to explore the health and emotional wellbeing of trans youth.

\section{Trans youth's resilience and emotional wellbeing}

With the recent trends in the UK towards asset-based approaches to health that recognise individuals', families' and communities' own capacities to promote their health and wellbeing, promoting resilience has become increasingly popular (Aranda and Hart 2015). In studies with black and mixed race trans youth (Singh et al. 2011, Singh 2013, Singh et al. 2014), resilience consistently meant being able to self-define, or define one's own gender, and use their own language to describe gender identity within their race or ethnicity, as well as being able to advocate for themselves in their school systems (Singh et al. 2011, Singh 2013).

\section{Schools and resilience}

Communities, schools and hospitals are seen as 'ideal settings' for programmes that promote health and wellbeing of young people (Miller et al. 2008). The school has an important role in promoting resilience (Knight 2007, PHE 2014), enhancing their mental health, and facilitating social and emotional development into adulthood (NICE 2009, DH 2013). Growing evidence suggests that the more connected young people feel to their school or community, the greater their overall wellbeing (Grieber et al. 2012, Young et al. 2013, Hackimer and Proctor 2015). Particular attention should be paid to the needs of minority groups, such as trans youth in order to promote social inclusion (Macnab 2013, Macnab et al. 2014, Sherriff et al. 2015). Here, joined-up thinking and active collaboration with young people, parents, teachers and health professionals is required to develop school-based clinics or youth services (Macnab et al. 2014, Mauriello et al. 2006). As a result of the specific health needs of trans youth related to their minority status and gaps identified in service 
delivery, research was undertaken to gain greater understanding of young people's views of what is needed to promote their emotional wellbeing and resilience. As part of wider research, this component included the views of trans youth themselves to determine what could be done to inform health improvement, commissioning and service delivery.

\section{Methods}

Participatory qualitative methods were utilised to engage young people in a study informed by an interpretivist frame. The research drew on realist principles to determine what works for whom, when, and under which circumstances (Pawson and Tilley 1997). This form of participatory inquiry shifts from a view of young people as passive objects of research, to young people as active participants or social actors who understand their own realities best (NCB 2011).

\section{Design, data collection and analysis}

Primary research data was generated via nineteen focus groups of young people in the UK, based at schools around East Sussex. Data for this paper are drawn from a cross sectional data set $(n=97)$ that included a focus group with trans young people $(n=5)$. The five trans youth who joined the focus group were aged 14-15 in Year $9(n=2)$, aged 16-17 in Year 10 and $11(\mathrm{n}=2)$, and aged 19 in Year $13(\mathrm{n}=1)$. The total sample of trans young people is small $(\mathrm{n}=5)$, as the UK Government estimates LGBT people account for $6 \%$ of the general population (McNamee et al. 2008). Trans people form $0.5 \%$ of the general population, or 1 in 200 people, accounting for an even smaller minority within LGBT groups (Bauer et al. 2015, Scheim and Bauer 2015). Young people were recruited via purposive sampling, with the help of gatekeepers at a trans youth club, to ensure a mix of socio-economic profiles and an age range of up to 19 years. The focus group size was small to ensure group members had the opportunity to interact and respond to each other in order to facilitate mutual exchange and psychological support (Sherriff et al. 2014). The group lasted around two hours, with the help of topic guides. Prior to data collection the guides were developed and agreed with relevant stakeholders that included young people. Example questions were: What factors help or hinder young people to cope, prevent stress and overcome difficult times? What are the factors and features of school that help or hinder young people? 
Focus group facilitators created the right atmosphere by using an ice-breaker at the onset, setting ground rules and by ensuring participants were psychologically, emotionally and physically safe (Sherriff et al. 2014). Focus groups were digitally voice recorded and data files were transcribed verbatim. Thematic analysis was used to scrutinise the dataset. Development of thematic categories were guided by key foci including. Categories were based on data where patterns and themes of analysis emerged. By adopting a team approach to analysis, the analytical processes were triangulated to increase research rigour. A project steering group met three times during the project. Young people were members of the project steering group and helped to co-produce findings later on (Sherriff 2015).

\section{Ethics}

The ethics and related practical issues required careful consideration, due to the vulnerability of young people. Ethical approval was gained via both the County Research Governance Panel and the Faculty Research and Ethical Governance Committee, based at the University. Specific ethical issues relevant to this participant group included clarification and reassurances about co-production, engaging meaningfully, minimising risk and putting safeguarding procedures in place. Detailed informed consent procedures were followed, where young people provided consent prior to participating in the focus group. A distress protocol was designed that mapped a pathway of action in the rare event of a young person becoming distressed during or after the focus group.

\section{Results}

\section{Resilience in the face of adversity}

The resilience and emotional wellbeing of trans young people is inextricably linked. Young people showed an awareness of how useful resilience can be in the face of adversity. Resilience is often seen as an ability to 'bounce back' following challenging life events or to persevere through adversity (Aranda and Hart 2015). Most participants spoke of resilience as an individual quality displayed in response to social, interpersonal or environmental stressors linked to their marginalisation, name calling, or social exclusion due to their gender non- 
conformity. This excerpt from data gives an indication of this adversity and how trans young people dealt with it.

T1: I think we're quite resilient, we have to be resilient to be ourselves.

T2: We do all have to be resilient every time we walk out of our front door, that is when we have to start being resilient, because you don't know what's going to come from where, like it is difficult but to be ourselves it's what we've got to do.

T1: It's useful. Just like it's like a protection word. If you call yourself resilient then you're going to get confidence from it because you know you're stronger than some people who would put you down because, in a sense, you're better than them, because you can take it on a daily basis whereas.. maybe they wouldn't be able to cope with it. (Trans Youth Club, Yrs 9-10)

Trans youth showed awareness of the benefit of being resilient in the face of adversity. Resilience acted as a form of psychological protection to deal with pressures young people face from peers, family and at school. Young people spoke of resilience predominantly as an individual responsibility with some reference to the factors such as marginalisation that underpin their adversity.

\section{Protective factors}

Trans young people recounted a range of protective factors that help them when things get tough. These activities included meditation, playing sport or making art when they feel down or upset. Young people who attended the trans youth club felt supported there, as they had a place where they could gather, laugh or speak to each other and make sense of challenging events. Here they experienced a strong bond of mutual trust and group identification, comparing this closeness to being a kind of family. Mutual support was unconditional and this gave them increased confidence to face the outside world where they were regarded as 'other' or different.

T1: We all get along here.

T3: Yeh, everybody just accepts each other. 
T1: There's no secrets or an air of mystery, we're all very close like family in a sense, so we can trust each other.

T3: Because everyone helps you to feel more confident in being yourself when you're here but also if you've got problems ... you can talk to other young people, you can talk to the staff and they help you to know how to be resilient outside of the group as well.

T3: You just meet people that are ... going through the same... difficulties as us, it's like we're all different... we all just have a laugh, we all get on, we know we can talk about anything with each other and we're not going to get judged for it. (Trans Youth Club, Yrs 9-10)

Young people experienced places where they could gather like the youth club as a place of safety. They mentioned the need for similar spaces in the community and at school where they could have time out, relax or speak to someone about challenging events, that could help them make sense of things. Findings were consistent with other research highlighting the need for safe spaces both in and out of school, and how these spaces and experiences of being supported are linked to meaningful social relationships, academic attainment and emotional wellbeing (McNamee et al. 2008, Whigmore et al. 2009, Hackimer and Proctor 2015). Young people suggested that this space should be separate to an 'isolation' room at school where they are 'parked' when displaying challenging behaviour. They wanted to choose when to visit this space to take time out, and when to re-enter class.

T3: ... if you're at school you just have to do what you're told all the time, but if say you're really struggling with bullying or whatever, if you could just, I don't know just be able to go out and do something that helps you, and then go back and deal with it. Because you don't get that opportunity you just have to be brave and deal with it.

I: Do you mean like taking time out?

T3: Sort of.. Well if I had a magic wand I'd like teachers to be able to tell when I'm struggling so I don't have to say anything and then be able to let me just go say like into another room and do some drawing or go, say like go into the gym and do some gym or all that sort of stuff, just, because it's really hard, you can't really tell teachers because they'll just be like, 'oh well just deal with it' like it's not their problem.

(Trans Youth Club, Yrs 9-10) 
Young people wanted their emotional needs acknowledged. A safe space would help where they could take 'time out' or talk to others when they are trying to make meaning of challenging events, like name calling, bullying or discrimination. For some young people sport acted as an activity where they could escape and that brought them together, however others found the gender divide in sport as problematic.

\section{Social inclusion}

Trans young people found gender-based norms limited their opportunities to participate in sport and physical activity. These gender-based restrictions often lead to social exclusion. Gendered norms around physical activity are entrenched historically, socially, and culturally in many schools and communities with much scope for change (Sherriff and Tungatt 2007). A young person transitioning from female to male spoke of his wish to participate in an allboys football team and the difficulties he encountered gaining access.

T3: It's quite difficult for me, I'd love to be able to be in a football team and stuff but it's just not socially acceptable to be trans and do sports like football, people don't think it's ok...

I: What would be ideal,... which kind of teams would you like to belong to or join?

T3: I'd just like to be in an all-boys football team. That's like the biggest thing, ..but I can't.

(Trans Youth Club, Yrs 9-10)

Opportunities for trans young people to participate in sport are limited due to the gender normative nature of organised sport. Sport is often arranged according to gender binaries where young people are segregated in teams for boys and girls. Organising sport and other activities along gendered binaries excludes young people who do not fit the normative male / female divide. They struggle to gain access as the non-binary nature of their gender is unrecognised or not accommodated. Moreover, arguments against social inclusion of all young people claim that competitive traditional gendered sports and activities foster team spirit and help prepare young people for adult life. However, there is no evidence to support these notions or to suggest that non-binary socially inclusive sport or activities are not capable of fostering team spirit and future life preparation (Sherriff and Tungatt 2007). Sport 
and activities for young people without the constraints of gender binaries could create opportunities for inclusion of those who lead non-normative lives.

\section{Resistance against bullying}

Trans young people spoke extensively of homophobic bullying and labelling as a shared stressor and potential obstacle to resilience. Their experiences were compounded by the perception that more could be done to address this form of discrimination.

T1: I go to an all-boys school so you always hear around school, you hear oh 'gay' or 'faggot'.... I was called it everywhere I went, 'oh he's gay' or... 'he's queer' and it really put me down. The school did nothing over it, it was like 'oh we'll deal with it don't worry' and then just slid it under the rug. Then ever since I came out they stopped saying it, which is quite weird.

I: Did you say they stopped saying it when you came out?

T1: Yeh. ... it was kind of like they were shocked. They kept saying it and then I came out and they kind of went 'oh'. They kind of paused for a minute... because... the definition of an insult is taking away someone's identity, so if you're calling someone gay and they are, it's not even an insult, it's just pointing out the obvious. So I think that's what happened at my school and they kind of just went 'oh we can't call him that now what do we do'? I was left on my own. (Trans Youth Club, Yrs 9-10)

Some young people show remarkable resilience when they are called names linked to their gender identity (trans) and sexuality (gay, lesbian, bisexual, queer). As a resilient move, this trans person came out to peers as gay, and thereby reclaimed terms that were once used against him. Once the young person self-identified, the discriminatory slants seemed to lose their power and name-calling subsided. For each young person, the way their gender and sexuality intersect is specific. Assumptions about their identity often miss the mark and are best avoided. Maybe practitioners and school nurses could ask young people how they self-define instead of fixing their identities. In this instance the young person identified as trans (gendered identity) with a sexual identity of being gay. At the intersection of their gender and sexuality, they were marginalised by being called names such as 'gay' or 'queer', however by claiming 
those identities they neutralised the power of those derogatory terms. Thus, any research with trans people have to consider the intersections of their gender and sexual identity, as their lives challenge heteronormative assumptions related to the male / female divide (Dhaenens 2013). The lives of trans youth help us move towards a non-binary understanding of gender, where identity inclduing their sexuality, is multifaceted and constantly evolving.

The shift towards non-binary gender is much needed as research in the USA (Grant $e t$ al. 2011, Singh et al. 2014) found homophobic bullying occurs frequently in the lives of trans young people with $78 \%$ reporting some form of harassment, and for $35 \%$ of these young people, leading to violence against them. Experiences of bullying is not always reported, however. McNamee et al. (2008) found $82 \%$ of teachers in the UK were aware of verbal homophobic bullying and $26 \%$ knew of physical homophobic bullying. Teachers were not always aware how to respond to victimisation. This highlights the need for training of professionals in schools, the community and health services to identify bullying and respond appropriately, to help protect the safety and emotional wellbeing of trans youth (Whigmore et al. 2009).

\section{Schools and health services}

Some trans young people felt misunderstood by both teachers and health professionals, particularly where they accessed health services. They thought teachers and health professionals could be better informed about trans issues and their specific emotional needs linked to experiences such as bullying or marginalisation. One trans young person spoke of their experience of accessing in-patient community adolescent mental health services (CAMHS) and the merits of practitioners using gender neutral language such as referring to them as 'they' instead of 'he' or 'she', or making facilities like toilets available that would include young people with non-normative gendered identities and sexualities.

T3: I think also, you mentioned mental health people like nurses. I ended up in hospital at a mental health place where people stay for under 18 s.. and they were good when it came to my normal mental health stuff, like average... like the reasons people were there were just for being sad and suicidal and stuff; but when it came to mentioning the fact that I was trans it was quite,.. it wasn't treated as well as it should 
have been. A couple of the nurses there, they just, one of them kept mis-gendering me... and they were a little bit funny about me using the boys' toilets and stuff like that at first.. And that shouldn't even matter because ..the toilets are individual anyway, so it doesn't even make a difference but, I don't know, I just think as well as normal teachers it could be developed more for mental health people as well. (Trans Youth Club, Yrs 9-10)

Trans young people mentioned that practitioners could do more to understand their needs and provide accessible support. Practitioners were hesitant to discuss issues related to gender and sexuality, resulting in the wrong pronouns being used when addressing them. Trans young people's ability to self-define is known to be essential to their wellbeing (Singh et al. 2014, Singh et al. 2015). Similar issues were raised in this research; school nurses and teachers could be better informed, offer greater levels of support and provide greater signposting to support in school, in the community or health service. Moreover, there was uncertainty as to whether there was a school nurse within their school, their availability and their overall location within the school. The UK Department of Health (2012) published a report from the view of young people that showed the need for greater accessibility of school nurses via a confidential booking service. School nurses could help both teachers and young people by being more visible and offering early help. Appointment systems should be flexible in terms of the time and the place where young people are seen (BYC 2011, DH 2012).

\section{Discussion}

This research is consistent with prior studies that indicate how inequalities influence the lives of trans people (Browne and Lim 2008a, Bauer et al. 2015). Trans youth are disproportionately affected by inequalities linked to their gendered identity (Hackimer and Proctor 2015, Nodin et al. 2015). Young people spoke of the adversity they experienced both at individual and institutional level as linked to being socially excluded from activities such as sport, or being labelled, or bullied by others due to name calling. Trans youth also spoke of their experiences of discrimination, where those who work with them at school, in the hospital or in the community do not understand how to address them, or meet their needs due to the evolving nature of their gendered identity and sexuality. Trans youth shared their views of the protective strategies they employed when facing adversity, such as meditation, art, gym and sport where they were free to join in without feeling judged. 
Similar to other studies that have explored resilience and trans young people's experiences, this research reaffirms that resilient strategies involve young people being deliberately proactive in accessing supportive educational systems, having a connection to a transaffirming community where they can reframe mental health challenges, and navigating relationships with family and friends (Singh et al. 2014, Hackimer and Proctor 2015). In addition, further research shows threats to trans youth's resilience include adults or significant others views of being trans as a phase they would grow out of (Singh 2013, Singh et al. 2014), together with fear of rejection or anticipation of discriminatory treatment in healthcare that then led to an avoidance of health providers (Bauer et al. 2014). As prior research suggests, gender policing was a common experience. This was most often seen in verbal assaults about claiming a trans identity or status, but significantly this hostility came not only from strangers, or the public, but regrettably from family and friends too (Singh et al. 2011, Singh 2013, Singh et al. 2014). With increasing research on trans people's lives, Singh et al (2014) suggest urgent further research is needed on the diversity of trans needs across the life span, but especially as to how educators and health professionals interact with young trans individuals and how to create trans affirming health and education systems to further their resilience (Singh et al. 2015).

Resilience is often mistakenly seen as a personal attribute or capacity, which ignores the social and structural factors that create the adversity (Aranda et al. 2012, Aranda and Hart 2015). In order to achieve lasting change, we have to tackle the causes of adversity for young people who lead non-normative gendered lives. Here we move away from formulations of resilience that locate the responsibility for resilience within the individual, towards systemic formulations that take account of the social determinants of health (Marmot 2010). Most recent theorisations of resilience aim at understanding the causes of adversity to help bring about change (Aranda and Hart 2015).

Practitioners, school nurses and teachers are challenged by the task of tackling systemic inequalities. Although there is some awareness of the lack of knowledge about service needs, there is also a lack of confidence in challenging transphobia, and knowledge of how to specifically support trans young people (Sherriff et al. 2011). For trans youth structural change would mean addressing the social determinants such as exclusion, labelling, bullying and discrimination. Whole systems approaches can incorporate structural changes to address inequalities, for example where sport is currently gender based. By opening access to sport 
beyond gendered norms in creating teams that are non-normative, opportunities for social inclusion of trans youth will follow.

In order to bring about change at a systems level, greater involvement of stakeholders like teachers, practitioners and school nurses are needed. Trans young people mentioned resources that help them persevere when things get tough, such as safe spaces in school or at youth clubs in the community, where they can feel connected to the broader LGBT community in a protected environment that enables access to advice and mutual support. Here they could make sense of challenging events such as labelling, bullying or discrimination. Research confirms the importance of trans young people remaining vigilant of everyday transphobic and discriminatory encounters or experiences (Singh 2013). Safety at school, in the community and at hospital can be achieved where young people feel as if they belong. Importantly, this sense of belonging and inclusion corresponded to a significant improvement in the emotional wellbeing and resilience of trans youth (Kertzner et al. 2009, Hackimer and Proctor 2015).

\section{Practitioners and school nurses}

Like the findings of this research, other studies suggest the contribution of practitioners and school nurses must be more effective. For example, young people want school nursing services that are more 'young people-friendly' and where anonymity is of primary importance (NCB 2011). Likewise, trans young people felt health practitioners in in-patient services could be better informed about their specific health needs and should learn or know how to accommodate non-normative gendered lives. Trans people found health practitioners unhelpful when their identified gender was not recognised (Singh et al. 2014), or when they were treated for conditions unrelated to their gendered identity (Bauer et al. 2014). This approach of health practitioners could reinforce trans youth's experiences of marginalisation, compounded by earlier experiences of discrimination or bullying (Johnson 2007, Browne and Lim 2008b). Irrespective of where trans young people access support, be it via health services, the community or the school, practitioners who work in these environments would benefit from training and greater openness to working in partnership with trans youth to help them define the health pathways best suited for them. 
Moreover, public health policies and programmes need to be designed to improve access to services that are trans positive and that promote health and wellbeing of trans communities across the lifespan (Pitts et al. 2009, Singh 2013). The UK Public Health Outcomes framework (PHE 2014) tackles health inequalities for LGBT communities and similarly some local authorities have added trans people to their campaigns for addressing issues such as workplace harassment, violence, hate crime and safety issues, housing and social care (Fish and Karban 2015). This desire for public recognition in policy is pivotal to the concerns of trans communities (Pitts et al. 2009). Achieving positive health and wellbeing requires personal self-recognition, along with interpersonal and social recognition for their identified gender. Therefore, full recognition of trans people's identity and status is key to meaningful interaction with healthcare professionals, and should be central to progressive healthcare policies and practice (Pitts et al. 2009).

\section{Conclusion}

This research engaged trans youth to explore their understanding and experiences of resilience and emotional wellbeing. During the study, trans young people shared their views of what is required to address their health needs. Trans youth wanted their views to be listened to and taken into account when designing services. They identified resilience as an individual capacity that allowed them to persevere through adversity, be that name calling, bullying, marginalisation or social exclusion, making them feel more resourceful and stronger in the face of that adversity. Being able to self-define their gendered identity, and sexuality, being recognised by peers, families, teachers, their school and practitioners, as well as having access to sport and safe spaces, where they didn't feel judged based on gendered norms, were all critical to the promotion of resilience.

However, resilience and emotional wellbeing has to be a collective responsibility shared by all stakeholders. Wider support is urgently needed from schools, practitioners and in the community to provide trans-affirming youth clubs, and health services to address specific care needs that stem from marginalisation. Moreover, structural change is needed at policy and a systems level to allow for joined-up thinking where health promotion initiatives and the practitioners, school nurses and teachers that deliver these services can facilitate change. Transformation at a systems level will ensure trans youth can remain resilient when they are understood, are safe at school, are free from bullying, and are socially included. 


\section{Acknowledgements}

The paper draws on insights gained from engagement and participation activity commissioned by East Sussex County Council, UK which aimed to provide greater understanding of the views and experiences of young people in East Sussex in relation to health improvement services and initiatives. ESCC developed the overall brief, main research questions and helped guide the work.

\section{References}

APA, 2013. Diagnostic and statistical manual of mental disorders: 5th edition. Washington: American Psychiatric Association.

Aranda, K. \& Hart, A., 2015. Resilient moves: Tinkering with practice theory to generate new ways of thinking about using resilience. Health, 14 (9), 355-371.

Aranda, K., Zeeman, L., Scholes, J. \& Santa-María Morales, A., 2012. The resilient subject: Exploring subjectivity, identity and the body in narratives of resilience. Health: An Interdisciplinary Journal for the Social Study of Health, Illness and Medicine, 16 (5), $548-563$.

Bauer, G., Scheim, A., Deutsch, M. \& Massarella, C., 2014. Reported emergency department avoidance, use, and experiences of transgender persons in Ontario, Canada: Results from a respondent-driven sampling survey. Annals of Emergency Medicine, 63 (6), 713-720.

Bauer, G., Scheim, A., Pyne, J., Travers, R. \& Hammond, R., 2015. Intervenable factors associated with suicide risk in transgender persons: A respondent driven sampling study in Ontario, Canada. BMC Public Health, 15 (525), 1-15.

Browne, C. \& Lim, J., 2008a. Count me in too. Trans people: Additional findings report. Brighton: Spectrum, U.O.B.A.

Browne, K. \& Lim, J., 2008b. Count me in too: Lgbt lives in Brighton and Hove - General health. Brighton: Spectrum, U.O.B.A.

Butler, J., 1993. Bodies that matter. On the discursive limits of 'sex'. London: Routledge.

Butler, J., 1999. Gender trouble: Feminism and the subversion of identity. New York: Routledge.

Butler, J., 2004. Undoing gender. London: Routledge.

British Youth Council, 2011. Our school nurse: Young people's views on the role of the school nurse. London: Department of Health. 
DH, 2012. Getting it right for children, young people and families: Maximising the contribution of the school nursing team - Vision and call to action. In Health, D.O. ed. London: Department of Health.

DH, 2013. Public mental health priorities: Investing in the evidence. Annual report of the chief medical officer. In Health, D.O. ed. London: Department of Health.

Dhaenens, F., 2013. Teenage queerness: Negotiating heteronormativity in the representation of gay teenagers in Glee. Youth Studies, 16 (3), 304-317.

Fish, J., 2008. Navigating queer street: Researching the intersections of lesbian, gay, bisexual and trans (lgbt) identities in health research. Sociological Research Online, 13 (1), 12.

Fish, J. \& Karban, K., 2015. Lesbian, gay, bisexual and trans health inequalities Cambridge: Policy Press.

Grant, J., Mottet, L., Tanis, J. \& Harrison, J., 2011. Injustice at every turn: A report of the national transgender discrimination survey. Washington DC: National Center for Transgender Equality.

Grieber, U., Rojatz, D., Simovska, V. \& Forste, R., 2012. Evidence for the effects of student participation in designing, planning, implementing and evaluating school health promotion: A systematic literature review. Vienna: Ludwig Blozman Institute.

Haas, A., Eliason, M., Mays, V., Mathy, R., Cochran, S., D'augelli, A., Silverman, M., Fisher, P., Hughes, T., Rosario, M., Russell, S. \& Malley, E., 2011. Suicide and suicide risk in lesbian, gay, bisexual, and transgender populations: Review and recommendations. Journal of Homosexuality, 58 (1), 10-51.

Hackimer, L. \& Proctor, S., 2015. Considering the community influence for lesbian, gay, bisexual, and transgender youth. Journal of Youth Studies, 18 (3), 277-290.

Hall, D., Jagose, A., Bebell, A. \& Potter, S., 2013. The Routledge queer studies reader. London: Routledge.

Hines, S., 2010. Queerly situated? Exploring negotiations of trans queer subjectivities at work and within community spaces in the UK. Gender, Place and Culture, 17 (5), 597-613.

Johnson, K., 2007. Transsexualism: Diagnostic dilemmas, transgender politics and the future of transgender care. In Clarke, V. \& Peel, E. eds. Out in psychology: Lesbian, gay, bisexual, trans and queer perspectives. Chichester: John Wiley \& Sons Ltd.

Johnson, K. \& Browne, C., 2012. Trans and intersex issues in health and care. Diversity and Equality in Health and Care, 9, 235-237.

Kertzner, R., Meyer, I., Frost, D. \& Stiratt, M., 2009. Social and psychological well-being in lesbian, gay men and bisexual: The effects of race, gender and sexual identity. American Journal of Orthopsychiatry, 79 (4), 500-510. 
King, M., Semleyn, J., Tai, S., Killaspy, H., Osborn, D., Popelyuk, D. \& Nazareth, I., 2008. A systematic review of mental disorder, suicide and deliberate self-harm in lesbian, gay and bisexual people. BMJ Psychiatry, 8 (1), 1-17.

Knight, C., 2007. A resilience framework: Perspectives for educators. Health Education, 107 (6), 543-555.

Levitt, H. \& Ippolito, M., 2014. Being transgender: Navigating minority stressors and developing authentic self-presentation. Psychology of Women Quarterly, 38 (1), 4664.

MacNab, A., 2013. The Stellenbosch consensus statement on health promoting schools. Global Health Promotion, 20 (1), 78-81.

MacNab, A., Gagon, F. \& Stewart, D., 2014. Health promoting schools: Consensus, strategies and potential health education. Health Education, 114 (3), 170-185.

Marmot, 2010. Fair society, healthy lives. Strategic review of health inequalities in England post 2010. In Health, D.O. ed., Masten AS: The Marmot Reveiw.

Mauriello, L., Driskell, M., Sherman, K., Johnson, S. \& Prochaska, J., 2006. Acceptability of a school-based intervention for the prevention of adolescent obesity Journal of School Nursing, 27 (5), 269-277.

McDermott, E., 2014. Asking for help online: Lesbian, gay, bisexual and trans youth, selfharm and articulating the 'failed' self. Health: An Interdisciplinary Journal for the Social Study of Health, Illness and Medicine, 19 (6),1-17.

McNamee, H., Lloyd, K. \& Schubotz, D., 2008. Same sex attraction, homophobic bullying and mental health of young people in Northern Ireland. Journal of Youth Studies, 11 (1), 33-46.

Miller, D., Gilman, R. \& Martens, M., 2008. Wellness promotion in schools: Enhancing students' mental and physical health. Psychology in the Schools, 45 (1), 5-15.

Nagoshi, J. \& Brzuzy, S., 2010. Transgender theory: Embodying research and practice. Journal of Women and Social Work, 25 (4), 431-443.

Nagoshi, J., Brzuzy, S. \& Terrell, H., 2012. Deconstructing the complex perceptions of gender roles, gender identity, and sexual orientation among transgender individuals. Feminism \& Psychology, 22 (4), 405-422.

Namaste, V., 2009. Undoing theory: The "transgender question" and the epistemic violence of Anglo-American feminist theory. Transgender Studies and Feminism: Theory, Politics, and Gendered Realities, 24 (3), 11-32.

NCB, 2011. Healthy lives; healthy people: Young people's views on being well and the future of public health. London: National Children's Bureau. 
NICE, 2009. Social and emotional wellbeing in secondary education. London: National Institute of Health and Care Excellence.

Nodin, N., Peel, E., Tyler, A. \& Rivers, I., 2015. The RARE research report lgb\&t mental health - risk and resilience explored. London: RARE.

Pawson, R. \& Tilley, N., 1997. Realistic evaluation. London: Sage.

PHE, 2014. Local action on health inequalities: Building children and young people's resilience in schools. Health equity evidence review. London: Public Health England.

Pitts, M., Couch, M., Mulcare, M., Croy, S. \& Mitchell, A., 2009. Transgender people in Australia and New Zealand: Health, well-being and access to health services. Feminism \& Psychology, 19 (4), 475-495.

Reczek, C. \& Umberson, D., 2012. Gender, health behavior, and intimate relationships: Lesbian, gay, and straight contexts. Social Sciences and Medicine, 74 (11), 17831790.

Rondahl, G., 2011. Heteronormativity in health care education programs. Nurse Education Today, 31 (4), 345-349.

Salih, S. \& Butler, J., 2011. The judith butler reader. Oxford: Blackwell.

Scheim, A. \& Bauer, G., 2015. Sex and gender diversity among transgender persons in Ontario, Canada: Results from a respondent-driven sampling survey. Journal of Sex Research, 52 (1), 1-14.

Sherriff, N., 2015. Listening before commissioning: Young people's views on health improvement in East Sussex. Accessible summary of findings for young people. Univeristy of Brighton: Centre for Health Research.

Sherriff, N., Cocking, C. \& Coleman, L., 2015. Engaging young people to inform health improvement commissioning and delivery in east sussex: Final report. Univeristy of Brighton: Centre for Health Research.

Sherriff, N., Gugglberger, L., Hall, C. \& Scholes, J., 2014. 'From start to finish': Practical and ethical considerations in the use of focus groups to evaluate sexual health service interventions of young people. Qualitative Psychology, 1 (2), 92-106.

Sherriff, N., Hamilton, W. \& Wigmore, S., 2011. "What do you say to them?" Investigating and supporting the needs of lesbian, gay, bisexual, trans, and questioning (lgbtq) young people. Journal of Community Psychology, 39 (8), 939-955.

Sherriff, N.S. \& Tungatt, M., 2007. The community sport and enhanced PESSCL pilot programme: Young people's perceptions of sport and physical activity in school and the community: ChildRIGHT, cR232, 20-23.

Singh, A., 2013. Transgender youth of color and resilience: Negotiating oppression and finding support. Sex Roles, 68 (11), 690-702. 
Singh, A., Hays, D. \& Watson, L., 2011. Strategies in the face of adversity: Resilience strategies of transgender individuals. Journal of Counseling \& Development, 89 (1), 20-27.

Singh, A., Meng, S. \& Hansen, A., 2014. "I am my own gender": Resilience strategies of trans youth. Journal of Counseling \& Development, 92 (2), 208-218.

Singh, A., Richmond, K. \& Burnes, T.R., 2015. Feminist participatory action research with transgender communities: Fostering the practice of ethical and empowering research designs. International Journal of Transgenderism, 14 (3), 93-104.

Whigmore, S., Sherriff, N. \& Bogen-Johnson, L., 2009. The sussex lgbtu training and development research partnership: Final report. Univeristy of Brighton: Centre for Health Research.

Young, I., St Leger, L. \& Buijs, G., 2013. School health promotion: Evidence for effective action. Utrecht: Schools for Health in Europe.

Zeeman, L., Aranda, K. \& Grant, A., 2014. Queering health: Critical challenges to normative health and healthcare. Ross-on-Wye: PCCS Books. 